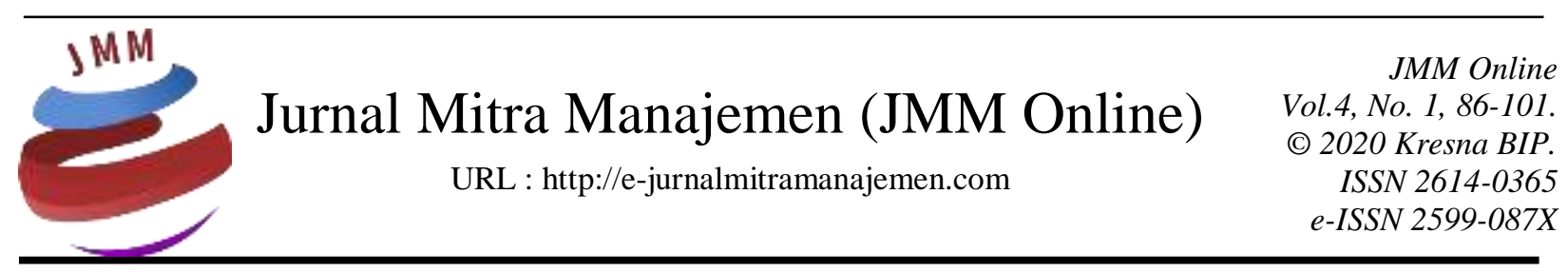

\title{
DIGITALISASI PERBANKAN : ADOPSI LAYANAN FINTECH OLEH USIA PRODUKTIF INDONESIA (STUDI PADA MASYARAKAT KOTA BANDUNG JAWA BARAT)
}

\author{
Madnur Syahri HSB ${ }^{1)}$, Andrieta Shintia Dewi ${ }^{2)}$ \\ Universitas Telkom
}

\section{INFORMASI ARTIKEL}

Dikirim : 13 Januari 2020

Revisi pertama : 20 Januari 2020

Diterima : 22 Januari 2019

Tersedia online : 31 Januari 2020

Kata Kunci : Adopsi Fintech, Usia Produktif Kota Bandung, Principal Component Analysis, Korelasi Pearson

Email : madnursyah27@gmail.com ${ }^{1)}$, andrieta.sd@gmail.com ${ }^{2)}$

\section{ABSTRAK}

Fintech di Indonesia berkembang dengan pesat dan meningkat signifikan. Pemerintah Indonesia juga memberikan dukungan berupa regulasi yang longgar terhadap layanan Fintech, sehingga memungkinkan industri perbankan akan tergantikan oleh Fintech. Tujuan penelitian ini menginformasikan hubungan variabel sosiodemografi, penilaian diri, dan karakteristik finansial terhadap conceivable use of Fintech secara parsial serta menjelaskan faktor yang mempengaruhi masyarakat usia produktif Kota Bandung dalam mengadopsi layanan Fintech. Teknik analisis data yang digunakan yaitu analisis korelasi pearson, principal component analysis dan regresi linier berganda. Temuan dalam penelitian ini adalah sosiodemografi, penilaian diri, serta karakteristik finansial berhubungan dengan conceivable use of Fintech secara parsial, dengan sub variabel utama sosiodemografi yaitu factor latar belakang rumah tangga dan faktor pendidikan, sub variabel utama variabel penilaian diri yaitu faktor kesabaran dan kepercayaan, faktor keputusan pembelian dan faktor risiko, serta sub variabel utama karakteristik finansial adalah faktor pengetahuan produk keuangan dan investasi, faktor menabung dan faktor pengetahuan keuangan. 


\section{PENDAHULUAN}

\section{Latar Belakang}

Adopsi teknologi di segala bidang adalah suatu keniscayaan, termasuk perbankan. Para pemangku kebijakan di dunia menilai, bank yang tidak mengadopsi teknologi atau beralih ke digital secara perlahan akan tergantikan. Salah satu industri yang bisa menggantikan peran bank adalah financial technology atau Fintech (katadata.co.id). Menurut Financial Stability Board (FSB), Fintech adalah suatu bentuk inovasi finansial berbasis teknologi yang dapat dapat menghasilkan model bisnis, aplikasi, proses atau produk baru dengan efek material terkait pada pasar keuangan, institusi, dan penyedia layanan keuangan. Sedangkan menurut The National Digital Research Centre (NDRC), Fintech merupakan innovation in financial services atau inovasi pada sektor finansial (business-law.binus.ac.id) Berdasarkan definisi di atas dapat dipahami bahwa pada prinsipnya Fintech adalah a fusion between technology and financial services. Penggunaan handpone sebagai layanan mobile banking dan investasi bisa dijadikan sebagai contoh perpaduan teknologi dengan sistem keuangan guna memberikan layanan keuangan yang lebih mudah diakses oleh masyarakat luas (business-law.binus.ac.id). Sehingga Fintech bertujuan memberikan kemudahan kepada masyarakat dalam mengakses produk-produk keuangan, mempermudah transaksi dan juga meningkatkan literasi keuangan (finansialku.com).

Berdasarkan Chair of the Financial Stability Board, Governor of the Bank of England Mark Carney melalui penelitian yang dilakukan oleh instansinya yaitu stress test terkait kondisi industri keuangan lima tahun ke depan pada 2017 menyatakana bahwa nilai atau fungsi perbankan akan terpecah (katadata.co.id). Hasil riset tersebut mengejutkan pemerintah Inggris. Oleh karena itu, pemerintah Inggris langsung melakukan pengkajian kebijakan yang mengatur Fintech. Di sisi yang lain, pemerintah Inggris juga mengkaji kebijakan yang memungkinkan Fintech agar mendapat ruang untuk berinovasi. Di Indonesia melalui Menteri Keuangan dinyatakan bahwa pemerintah akan menerapkan kebijakan yang longgar atau light touch regulation terkait ekonomi digital termasuk Fintech (katadata.co.id). Sehingga dengan kondisi tersebut, apakah transformasi tersebut mampu memberikan manfaat yang maksimal bagi perekonomian dan masyarakat di Indonesia terlepas dari perbankan milik negara ataupun bukan.

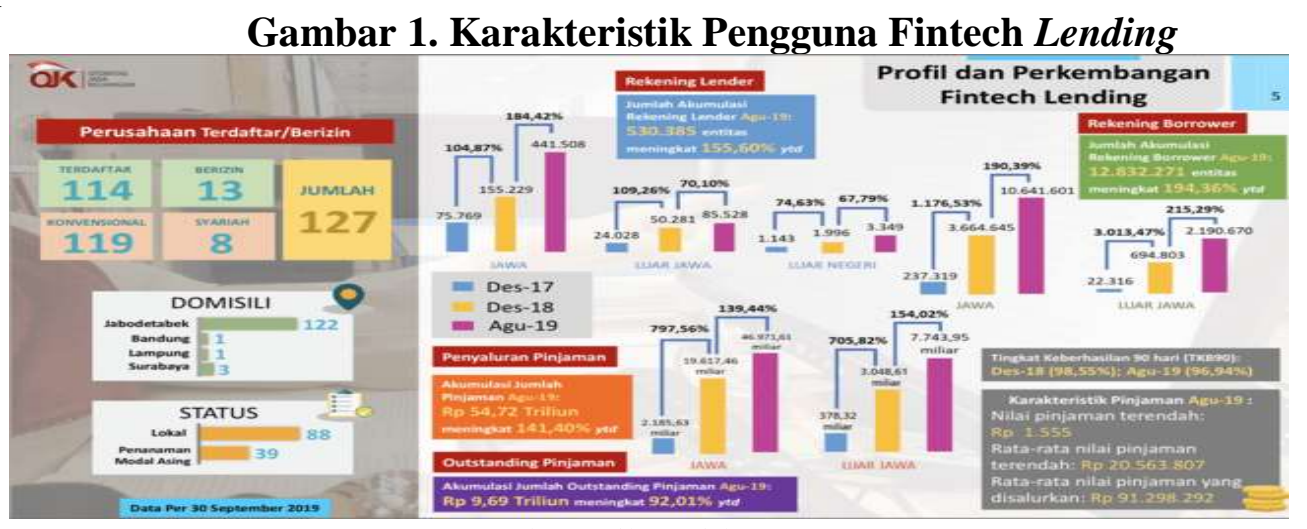

Sumber: ojk.co.id (2019) 
Menurut data dari OJK, sampai bulan Agustus 2019 berdasarkan gambar diatas, penyaluran pinjaman Fintech mencapai Rp54,72 triliun. Jumlah penyaluran tersebut naik 170,73\% dari awal tahun 2018 yang tercatat senilai Rp22,67 triliun. Angka ini masih tergolong kecil, karena berdasarkan penelitian OJK pada tahun 2016, terdapat kesenjangan pendanaan di Indonesia sebesar Rp989 triliun per tahunnya. Kesenjangan tersebut disebabkan kebutuhan pendanaan sebesar Rp1.649 triliun tidak dapat dipenuhi oleh lembaga keuangan yang hanya memiliki total aliran dana Rp660 triliun (ojk.co.id). Menurut model penerimaan teknologi/technology acceptance model (TAM) Davis (1989), niat pengguna untuk mengadopsi teknologi baru ditentukan oleh kegunaan yang dirasakan dan kemudahan penggunaan. Penelitian terbaru menggunakan TAM untuk memprediksi adopsi Fintech, seperti pembayaran mobile di Taiwan (Wu dan Wang, 2005), pembayaran crypto di Belanda (Jonker, 2019), e-ticket di Finlandia (Mallat et al., 2009), dan e-commerce (Smith et al., 2014) diantara layanan lainnya. Namun, beberapa penelitian, seperti Mangin et al. (2014), Aldás-Manzano et al. (2009), Amin (2009), Featherman dan Pavlou (2003), dan Wang et al. (2003), berpendapat bahwa kenyamanan konsumen saja tidak dapat sepenuhnya menjelaskan meningkatnya popularitas teknologi dan layanan baru di industri keuangan. Mereka menunjukkan, bahwa terutama dimensi kepribadian, kognitif, dan perilaku konsumen berdampak pada adopsi produk Fintech. Secara khusus, mereka mengusulkan memperluas TAM menggunakan langkah-langkah risiko yang dirasakan dan kredibilitas atau kepercayaan yang dirasakan untuk menangkap masalah keamanan dan privasi konsumen tentang kegiatan perbankan digital.

Jika Fintech dapat menghasilkan tingkat kepuasan pelanggan yang lebih tinggi melalui layanan dan penawaran yang lebih baik (misalnya: tarif dan biaya yang lebih rendah, proses yang lebih cepat, lebih fleksibel, dan transparan, dll.), maka mereka dapat meningkatkan ketidakpuasan konsumen dengan pemain tradisional untuk meningkatkan pangsa pasar mereka (Maier, 2016). Namun, sejauh ini, beberapa penelitian telah menganalisis perilaku switching bank oleh konsumen (Manrai dan Manrai, 2007). Diharapkan perubahan ini sebagai pemahaman yang lebih baik tentang adopsi inovasi di sektor keuangan oleh pelanggan khususnya usia produktif menjadi semakin penting, karena, misalnya, penilaian implikasi stabilitas keuangan Fintech (FSB, 2017), dan sejumlah implikasi lainnya. Pembubaran fungsi bank oleh berbagai jenis perusahaan menggunakan teknik digital, dan adopsi layanan perbankan digital sepenuhnya oleh pelanggan, adalah topik yang kurang dipahami dan dipahami. Oleh karena itu, penelitian ini berkontribusi pada literatur Fintech yang baru, serta penelitian terbatas tentang apa yang menyebabkan pelanggan untuk mengadopsi layanan perbankan digital sepenuhnya dan memotivasi mereka untuk beralih ke Fintech.

\section{Rumusan Masalah}

Berdasarkan latar belakang diatas maka rumusan masalah pada penelitian ini adalah sebagai berikut :

1. Apakah terdapat hubungan antara sosiodemografi terhadap conceivable use of Fintech?

2. Apakah terdapat hubungan antara penilaian diri terhadap conceivable use of Fintech? 
3. Apakah terdapat hubungan antara karakteristik finansial terhadap conceivable use of Fintech?

4. Apakah faktor-faktor yang paling mempengaruhi keputusan masyarakat usia produktif Kota Bandung dalam conceivable use of Fintech?

\section{Tujuan Penelitian}

Berdasarkan rumusan masalah diatas maka tujuan pada penelitian ini adalah sebagai berikut :

1. Untuk mengetahui apakah terdapat hubungan antara sosiodemografi terhadap conceivable use of Fintech.

2. Untuk mengetahui apakah terdapat hubungan antara penilaian diri terhadap conceivable use of Fintech.

3. Untuk mengetahui apakah terdapat hubungan antara karakteristik finansial terhadap conceivable use of Fintech.

4. Untuk mengetahui faktor-faktor yang paling mempengaruhi keputusan masyarakat usia produktif Kota Bandung dalam conceivable use of Fintech.

\section{KAJIAN PUSTAKA}

\section{Manajamen Keuangan}

Manajemen keuangan adalah sistem prinsip dan metode untuk pengembangan serta implementasi keputusan manajerial terkait dengan pembentukan, distribusi dan penggunaan sumber daya keuangan untuk memastikan ukuran dan struktur aset yang diperlukan sesuai dengan tujuan dan sasaran perusahaan (Lisovskaya, 2006; dalam Khominich et al., 2016). Mengingat bahwa manajemen juga berkaitan erat dengan sebutan sistem maka manajemen keuangan juga dapat diartikan sebagai tindakan sistem untuk mengoptimalkan model keuangan perusahaan (Khominich et al., 2016).

\section{Fungsi Spesialisasi Manajemen Keuangan}

Aspek spesialisasi alokasi dasar arah manajemen kuangan, sesuai yang disampaikan oleh Karaseva (2015) antara lain sebagai berikut :

1. Pembentukan struktur modal keuangan

2. Penciptaan asset

3. Manajemen aset yang beredar

4. Manajemen aset tidak lancer

5. Mengelola investasi

6. Manajemen dan pembentukan sumber daya keuangan sendiri

7. Pengelolaan dana pinjaman

8. Manajemen risiko keuangan

Dalam pelaksanaan fungsi umum, spesialisasi maupun aspek alokasi dasar arah manajemen keuangan tersebut tidak dapat berjalan apabila tidak ada suatu badan yang menjalankan fungsi sebagai lembaga keuangan.

\section{Lembaga Keuangan}

Lembaga keuangan merupakan bagian dari sistem keuangan dalam ekonomi modern yang melayani masyarakat pemakai jasa-jasa keuangan. Lembaga keuangan 
sering disebut sebagai lembaga intermediasi keuangan (financial intermediary) ( $\mathrm{Hu}$ et al., 2019).

\section{Perbankan}

Persaingan antar bank dalam menghimpun dana dari masyarakat dan menyalurkannya kembali dalam bentuk kredit, dalam prakteknya banyak yang menyimpang dari aturan-aturan yang berlaku dalam dunia bisnis perbankan seperti tidak mengindahkan prinsip kehati-hatian bank (prudential banking) dengan memberikan kredit tak terbatas pada nasabah satu kelompok dengan perbankan tersebut, sehingga seringkali merugikan para deposan dan investor serta berdampak pada perekonomian negara yang diakibatkan kecenderungan meningkatnya kredit bermasalah atau macet (Rai dan Purnawati, 2017).

\section{Financial Technology (Fintech)}

Menurut laporan industri nilai investasi di perusahaan-perusahaan Fintech telah tumbuh sebesar 75\% pada tahun 2015 menjadi USD 22,3 miliar dibandingkan tahun sebelumnya (Skan et al., 2016). Secara total lebih dari USD 50 miliar telah diinvestasikan secara global di perusahaan-perusahaan Fintech sejak 2010 (Skan et al., 2016). Populasi dari perusahaan-perusahaan Fintech diperkirakan saat ini melampaui 12.000 di seluruh dunia (Drummer et al., 2016).

\section{Conceivable Use of Financial Technology (Fintech)}

Menurut Junger dan Mietzner (2019) Faktor-faktor yang mempengaruhi penggunaan layanan Fintech adalah sebagai berikut.

1. Sociodemographic Characteristic/ Karakteristik Sosiodemografik

Sociodemographic characteristic terdiri atas marital status/status pernikahan, highest level of education/level pendidikan tertinggi, dan employment/kepegawaian (Bundesbank, 2016; dalam Junger dan Mietzner, 2019).

2. Self Assessment/ Penilaian Diri

Tingkat kepercayaan sesorang terhadap orang banyak merupakan dasar dari self assessment. Melihat sejauh mana sesorang dapat mepercayai individu atau suatu kelompok masyarakat. Self assessment ini sering disebut dengan trust general. Selain itu juga terdapat beberapa hal yang menjadi tolak ukur untuk melakukan self assessment/penilaian diri antara lain adalah trust advisor, price, transparency, risk, patience, finance knowledge dan risk tolerance (Kramer, 2016; dalam Junger dan Mietzner, 2019)

3. Financial Characteristic/ Karakteristik Keuangan

Financial Characteristic seseorang dapat diukur menggunakan tingkat keinginan dan kebiasaan orang tersebut untuk menabung atau menyimpan uang miliknya (Bundesbank, 2016; dalam Junger dan Mietzner, 2019). Mietzner dan Junger (2019) menyatakan bahwa karakteristik finansial seseorang dapat dinilai dari jumlah banyaknya uang yang ditabung oleh mereka. Namun pengetahuan akan produk-produk investasi juga dibutuhkan, bahwa untuk mengukur financial characteristic dapat menggunakan tingkat pengetahuan terhadap produk-produk keuangan (OECD, 2011; dalam Junger dan Mietzner, 2019). 


\section{Kerangka Pemikiran}

\section{Gambar 2. Kerangka Pemikiran}

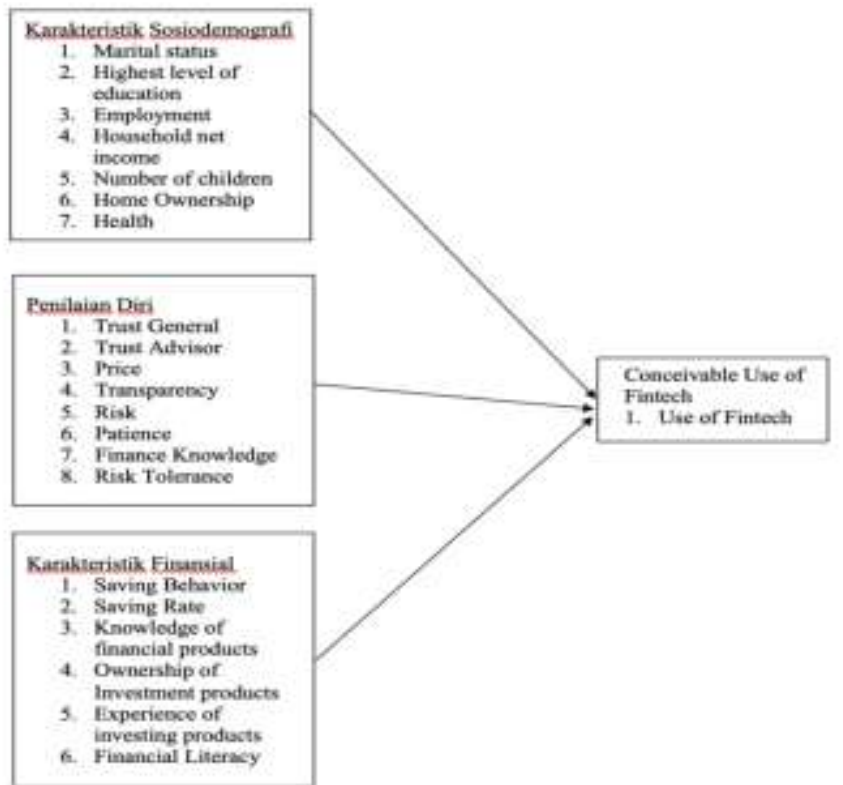

Sumber: Junger dan Mietzner (2019)

\section{Hipotesis}

Berdasarkan kerangka pemikiran diatas maka hipotesis pada penelitian ini adalah sebagai berikut.

H1 :Terdapat hubungan antara dimensi karateristik sosiodemografik dengan conceivable use of Fintech.

$\mathrm{H} 2$ :Terdapat hubungan antara dimensi penilaian diri dengan conceivable use of Fintech.

H3 :Terdapat hubungan antara dimensi karakteristik finansial dengan conceivable use of Fintech.

\section{METODE PENELITIAN}

\section{Jenis Penelitian}

Penelitian ini berdasarkan metodenya merupakan penelitian kuantitatif, berdasarkan tujuannya merupakan penelitian kausal, berdasarkan tipe penyelidikannya merupakan penelitian korelasional, berdasarkan waktu pelaksanaan merupakan penelitian cross section.

\section{Tempat, Waktu dan Media Penelitian}

Tempat penelitian ini adalah Kota Bandung, Jawa Barat, Indonesia. Media yang digunakan pada penelitian ini adalah kuisioner dan waktu penelitian OktoberDesember 2019. 


\section{Sampel}

Pada penelitian ini, teknik pengambilan sampel yang digunakan adalah nonprobability sampling. Non-probability sampling adalah teknik sampling yang tidak memberikan kesempatan yang sama bagi setiap unsur atau anggota populasi untuk dijadikan sampel pada penelitian. Sedangkan penentuan pengambilan jumlah responden (sampel) dilakukan melalui teknik quota sampling. Penentuan jumlah sampel minimal dihitung dengan menggunakan rumus Slovin, yaitu :

Keterangan:

$$
n=\frac{N}{1+N e^{2}}
$$

$\mathrm{n}=$ ukuran sampel.

$\mathrm{N} \quad=$ ukuran populasi.

e $\quad=5 \%$, konstanta kelonggaran ketidaktelitian karena kesalahan pengambilan keputusan sampel yang masih dapat untuk ditolerir. Adapun perhitungan penentuan jumlah sampel minimal pada penelitian kali ini adalah sebagai berikut :

$$
\begin{aligned}
n= & \frac{699.395}{1+699.395(0,05)^{2}} \\
& n=\frac{699.395}{1.749,4875} \\
n= & 399,771361613 \sim 400
\end{aligned}
$$

Berdasarkan perhitungan dengan rumus Slovin tersebut dihasilkan angka 399,771361613, sehingga untuk memudahkan perhitungan selanjutnya, maka angka tersebut dibulatkan menjadi 400. Jadi jumlah sampel minimal yang akan diteliti pada penelitian kali ini berjumlah sebanyak 400 orang responden.

\section{Teknik Pengumpulan Data}

Sumber data primer pada penelitian kali ini adalah hasil kuesioner yang disebar oleh peneliti dan sumber data sekunder pada penelitian kali ini berasal dari buku, jurnal, artikel website, berita online, penelitian sebelumnya, maupun sumber relevan yang lain.

\section{Teknik Analisis Data}

Teknik analisis data yang digunakan pada penlitian ini adalah analisis statistik deskriptif, analisis korelasi pearson, regresi linier berganda dan principal component analysis. Untuk rumus umum regresi linier berganda tersebut adalah :

$$
Y=a+b X 1+b X 2+b X 3
$$

Keterangan:

$$
\begin{array}{ll}
\mathrm{Y} & =\text { Conceivable Use of Financial Technology } \\
\mathrm{a} & =\text { Konstanta } \\
\mathrm{X} 1 & =\text { Sosiodemografi } \\
\mathrm{X} 2 & =\text { Penilaian Diri } \\
\mathrm{X} 3 & =\text { Karakteristik Finansial }
\end{array}
$$




\section{HASIL PENELITIAN DAN PEMBAHASAN Analisis Statistik Deskriptif}

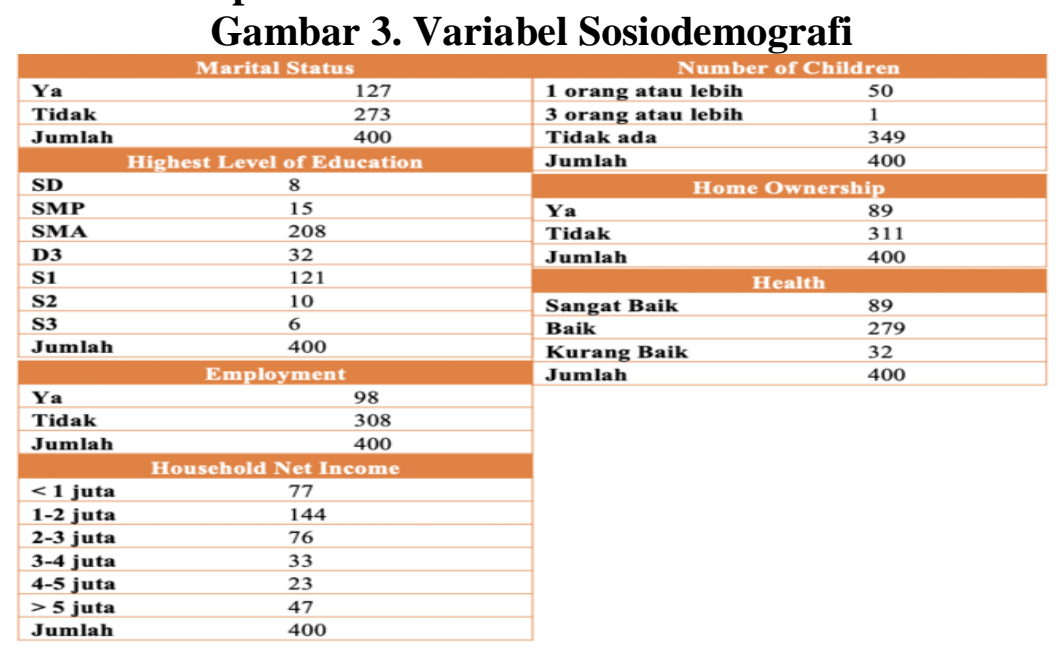

Sumber : Hasil Penelitian, diolah (2019)

Berdasarkan gambar disamping diketahui bahwa responden didominasi oleh masyarakat usia produktif Kota Bandung yang sudah menikah dengan pendidikan tertinggi yaitu SMA, belum bekerja dengan penghasilan atau uang saku 1-2 juta rupiah, belum memilki tanggungan anak, belum memiliki rumah sendiri serta tingkat kesehatan dalam kategori baik.

Gambar 4. Variabel Karakteristik Finansial

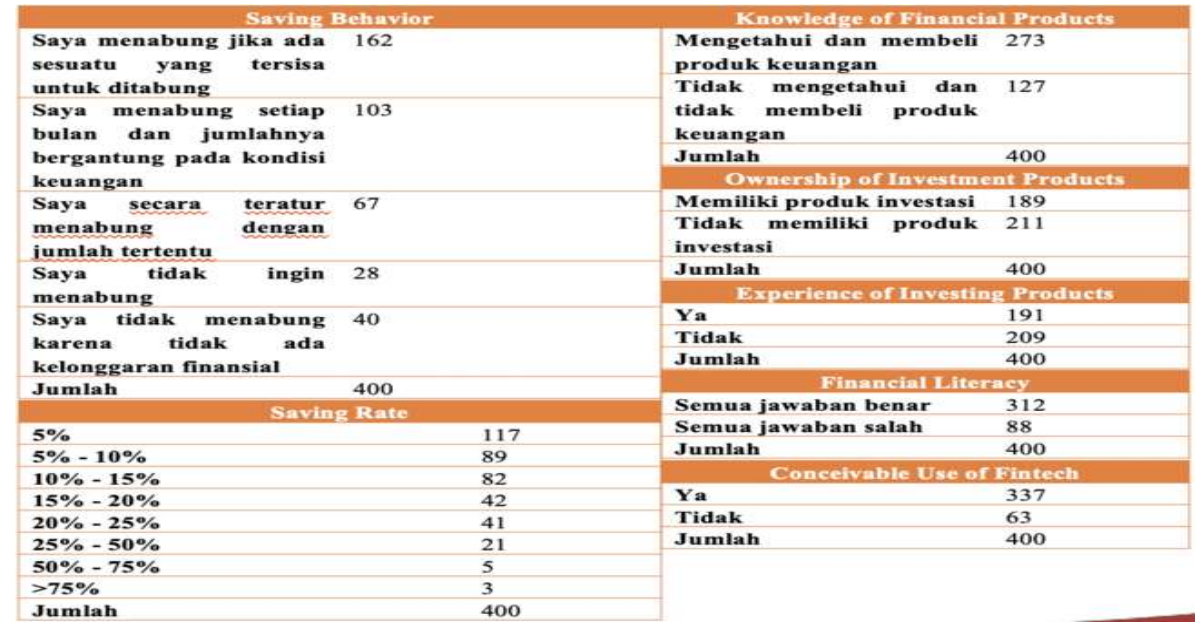

Sumber : Hasil Penelitian, diolah (2019)

Berdasarkan gambar disamping diketahui bahwa responden didominasi oleh masyarakat usia produktif Kota Bandung yang menabung apabila memiliki sesuatu yang tersisa untuk ditabung dengan tingkat tabungan sebesar 5\%, rata-rata mengetahui dan membeli produk keuangan dengan didominasi tidak memiliki produk investasi, tidak memiliki pengalaman investasi, pegetahuan keuangan yang cukup baik, dan siap untuk mengadopsi Fintech. 


\section{Gambar 5. Garis Kontinum Variabel Penilaian Diri}

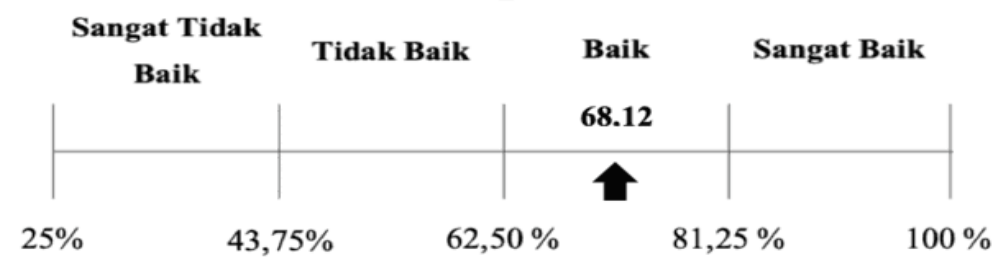

Sumber : Hasil Penelitian, diolah (2019)

Rata-rata skor untuk variabel penilaian diri sebesar 1089,75 dengan persentase sebesar 68,12\%. Hal ini menunjukan trust general, trust advisor, price, transparency, risk, patience, finance knowledge, risk tolereance responden dalam penilaian diri dalam keadaan baik. Penilaian diri pada masyarakat usia produktif Kota Bandung dimulai dari rasa percaya terhadap orang lain ataupun penasihat keuangan, sensitivitas terhadap harga, dan rela atau tidaknya untuk pengambilan risiko terhadap produk investasi ataupun keuangan. Jadi jika seseorang tersebut tidak secara umum terlalu percaya terhadap banyak orang, mengetahui beberapa produk investasi dan keuangan, serta rela untuk mengambil risiko, maka seseorang tersebut akan lebih mungkin dan mampu untuk menerima serta menggunakan teknologi keuangan.

\section{Analisis Korelasi Pearson}

Tabel 1. Hasil Uji Korelasi Pearson

\begin{tabular}{|c|c|c|c|c|c|}
\hline \multicolumn{6}{|c|}{ Correlations } \\
\hline & & $\begin{array}{l}\text { Conceivable } \\
\text { Use Of } \\
\text { Fintech }\end{array}$ & $\begin{array}{c}\text { Sosiodemogr } \\
\text { afi }\end{array}$ & Penilaian Diri & $\begin{array}{c}\text { Karakteristik } \\
\text { Finansial }\end{array}$ \\
\hline \multirow{3}{*}{$\begin{array}{l}\text { Conceivable Use of } \\
\text { Fintech }\end{array}$} & Pearson Correlation & 1 & $.129^{\star}$ & -.053 & $.143^{k \prime}$ \\
\hline & Sig. (2-tailed) & & .010 & .293 & .004 \\
\hline & $N$ & 400 & 400 & 400 & 400 \\
\hline \multirow[t]{3}{*}{ Sosiodemografi } & Pearson Correlation & $.129^{x}$ & 1 & .055 & $.233^{\mathrm{k}}$ \\
\hline & Sig. (2-tailed) & .010 & & .271 & .000 \\
\hline & $\mathrm{N}$ & 400 & 400 & 400 & 400 \\
\hline \multirow[t]{3}{*}{ Penilaian Diri } & Pearson Correlation & -.053 & .055 & 1 & .084 \\
\hline & Sig. (2-tailed) & .293 & .271 & & .095 \\
\hline & $N$ & 400 & 400 & 400 & 400 \\
\hline \multirow[t]{3}{*}{ Karakteristik Finansial } & Pearson Correlation & $.143^{\pi *}$ & $.233^{\mathrm{k}}$ & .084 & 1 \\
\hline & Sig. (2-tailed) & .004 & .000 & .095 & \\
\hline & $\mathrm{N}$ & 400 & 400 & 400 & 400 \\
\hline
\end{tabular}

Sumber : Hasil Penelitian, diolah (2019)

Berdasarkan tabel diatas dapat disimpulkan sebagai berikut:

a. Nilai $r$ korelasi antara variabel conceivable use of financial technology dan variabel sosiodemografi sebesar 0,129 dengan nilai sig $<0,05$, artinya kedua variabel memiliki korelasi yang positif dengan tingkat hubungan termasuk dalam kategori sangat lemah. Hal ini berarti semakin menyesuaikan sosiodemografi sesorang maka semakin memungkinkan seseorang tersebut untuk menggunakan teknologi keuangan. 
b. Nilai $r$ korelasi antara variabel conceivable use of financial technology dan variabel penilaian diri sebesar -0,053 dengan nilai sig > 0,05, artinya kedua variabel memiliki korelasi yang negatif dengan tingkat hubungan termasuk dalam kategori sangat lemah. Hal ini berarti semakin kurang baik penilaian diri seseorang maka semakin rendah tidak memungkinkan seseorang tersebut untuk menggunakan teknologi keuangan dan penilaian diri seseorang tidak begitu menentukan seseorang untuk menggunakan teknologi keuangan.

c. Nilai $\mathrm{r}$ korelasi antara variabel conceivable use of financial technology dan variabel karakteristik finansial sebesar 0,143 dengan nilai sig < 0,05, artinya kedua variabel memiliki korelasi yang positif dengan tingkat hubungan termasuk dalam kategori sangat lemah. Hal ini berarti semakin baik karakteristik finansial seseorang maka akan semakin memungkinkan seseorang tersebut untuk menggunakan teknologi keuangan.

\section{Analisis Regresi Linier Berganda}

Tabel 2. Hasil Uji Regresi Linier Berganda

\begin{tabular}{|c|c|c|c|c|c|c|c|c|}
\hline \multicolumn{9}{|c|}{ Coefficients $^{a}$} \\
\hline & & \multicolumn{2}{|c|}{ Unstandardized Coefficients } & \multirow{2}{*}{$\begin{array}{c}\text { Standardized } \\
\text { Coefficients } \\
\text { Beta }\end{array}$} & \multirow[b]{2}{*}{$t$} & \multirow[b]{2}{*}{ Sig. } & \multicolumn{2}{|c|}{ Collinearity Statistics } \\
\hline \multicolumn{2}{|c|}{ Model } & B & Std. Error & & & & Tolerance & VIF \\
\hline \multirow[t]{4}{*}{1} & (Constant) & .695 & .108 & & 6.449 & .000 & & \\
\hline & Sosiodemografi & .013 & .007 & .101 & 1.946 & .052 & .951 & 1.051 \\
\hline & Penilaian Diri & -.010 & .006 & -.081 & -1.586 & .114 & .978 & 1.022 \\
\hline & Karakteristik Finansial & .021 & .006 & .167 & 3.218 & .001 & .950 & 1.053 \\
\hline
\end{tabular}

Sumber : Hasil Penelitian, diolah (2019)

Berdasarkan tabel diatas diperoleh nilai koefisien yang akan digunakan pada regresi linear berganda. Sehingga persamaan regresi linear berganda pada penelitian ini adalah:

$$
Y=0,695+0,013 X 1-0,010 X 2+0,021 X 3
$$

Adapun hasil dari persamaan regresi linier berganda tersebut dapat diuraikan sebagai berikut:

Nilai konstanta $(\alpha)=0,695$ merupakan nilai konstan, yang diartikan bahwa jika variabel sosiodemografi, variabel penilaian diri dan variabel karakteristik finansial konstan maka conceivable use of financial technology masyarakat usia produktif Kota Bandung adalah sebesar 0,695. Nilai koefisien regresi variabel sosiodemografi sebesar 0,013 dan variabel karakteristik finansial sebesar 0,021 serta bertanda positif artinya bahwa setiap kenaikan 1 satuan variabel sosiodemografi dan 1 satuan variabel karakteristik finansial maka akan meningkatkan conceivable use of financial technology masyarakat usia produktif Kota Bandung sebesar 0,013 dan 0,021, dan nilai koefesien variabel penilaian diri sebesar -0,010 dan bertanda negatif artinya bahwa setiap penurunan 1 satuan variabel penilaian diri akan menurunkan conceivable use of financial technology masyarakat usia produktif Kota Bandung. 
Principal Component Analysis

Tabel 3. Hasil Uji Analisis Faktor Variabel Sosiodemografi

\begin{tabular}{|l|c|c|}
\hline \multicolumn{3}{|c|}{ Rotated Component Matrix } \\
& \multicolumn{2}{c}{ Component } \\
& 1 & 2 \\
\hline Marital Status & .617 & .167 \\
\hline $\begin{array}{l}\text { Highest Level of } \\
\text { Education }\end{array}$ & .333 & .630 \\
\hline Employment & .698 & .046 \\
\hline Household Net Income & .677 & .058 \\
\hline Number Of Children & .695 & -.054 \\
\hline Home Ownership & .713 & -.008 \\
\hline Health & .187 & -.806 \\
\hline $\begin{array}{l}\text { Extraction Method: Principal Component Analysis. } \\
\text { Rotation Method: Varimax with Kaiser } \\
\text { Normalization. } \\
\text { a. Rotation converged in 3 iterations. }\end{array}$ \\
\hline
\end{tabular}

Sumber : Hasil Penelitian, diolah (2019)

Berdasarkan tabel disamping dapat diketahui bahwa pada variabel sosiodemogradi terdapat dua faktor utama yaitu faktor 1 dan faktor 2 . Penentuan input variabel ke faktor tertentu mengikut pada besar korelasi antara sub variabel dengan faktor, yaitu kepada korelasi yang besar. Dengan demikian maka faktor dan anggotanya adalah:

1. Faktor 1 (latar belakang rumah tangga) terdapat lima sub variabel sebagai anggotanya yaitu marital status, employment, houshold net income, number of children, dan home ownership.

2. Faktor 2 (pendidikan dan kesehatan) terdapat dua sub variabel sebagai anggotanya yaitu highest level of education dan health.

Tabel 4. Hasil Uji Analisis Faktor Variabel Penilaian Diri

\begin{tabular}{|c|c|c|c|}
\hline \multicolumn{4}{|c|}{ Rotated Component Matrix ${ }^{a}$} \\
\hline & \multicolumn{3}{|c|}{ Component } \\
\hline & 1 & 2 & 3 \\
\hline Trust General & .768 & .143 & .003 \\
\hline Trust Advisor & .782 & .116 & .065 \\
\hline Price & .192 & .772 & .062 \\
\hline Transparency & .107 & .804 & -.044 \\
\hline Risk & .122 & -.036 & .784 \\
\hline Patience & .707 & .045 & .165 \\
\hline Finance Knowledge & .007 & .641 & .424 \\
\hline Risk Tolerance & .079 & .200 & .819 \\
\hline \multicolumn{4}{|c|}{$\begin{array}{l}\text { Extraction Method: Principal Component Analysis. } \\
\text { Rotation Method: Varimax with Kaiser Normalization. }\end{array}$} \\
\hline
\end{tabular}

Sumber : Hasil Penelitian, diolah (2019) 
Tabel disamping dapat diketahui bahwa pada variabel penilaian diri terdapat tiga faktor utama yaitu faktor 1, faktor 2 dan faktor 3. Penentuan input variabel ke faktor tertentu mengikut pada besar korelasi antara sub variabel dengan faktor, yaitu kepada korelasi yang besar. Dengan demikian maka faktor dan anggotanya adalah:

1. Faktor 1 (kesabaran dan kepercayaan) terdapat tiga sub variabel sebagai anggotanya yaitu trust general, trust advisor, dan patience.

2. Faktor 2 (keputusan pembelian) terdapat tiga sub variabel sebagai anggotanya yaitu price, transparency, dan finance knowledge.

3. Faktor 3 (risiko) terdapat dua sub variabel sebagai anggotanya yaitu risk dan risk tolerance.

Tabel 5. Hasil Uji Analisis Faktor Variabel Karakteristik Finansial

\begin{tabular}{|c|c|c|c|}
\hline \multicolumn{4}{|c|}{ Rotated Component Matrix ${ }^{a}$} \\
\hline & \multicolumn{3}{|c|}{ Componeint } \\
\hline & 1 & 2 & 3 \\
\hline Saving Baravior & .014 & .804 & .239 \\
\hline Saving Rate & .250 & .794 & -.165 \\
\hline $\begin{array}{l}\text { Knoviledje of Financial } \\
\text { Products }\end{array}$ & .671 & -.066 & .369 \\
\hline $\begin{array}{l}\text { Oweership oflmestmert } \\
\text { Products }\end{array}$ & .837 & 110 & -.052 \\
\hline $\begin{array}{l}\text { Experiente of investing } \\
\text { Products }\end{array}$ & .686 & 313 & -.073 \\
\hline Financial Literacy & .032 & .065 & .909 \\
\hline \multicolumn{4}{|c|}{$\begin{array}{l}\text { Extraction Yethot: Princioal Component Analisis. } \\
\text { Rotation Hethot Varimax with Ka ser Normalication }\end{array}$} \\
\hline \multicolumn{4}{|c|}{ a. Rotation converged in 5 iterations. } \\
\hline
\end{tabular}

Sumber : Hasil Penelitian, diolah (2019)

Berdasarkan tabel diatas dapat diketahui bahwa pada variabel penilaian diri terdapat tiga faktor utama yaitu faktor 1, faktor 2 dan faktor 3. Penentuan input variabel ke faktor tertentu mengikut pada besar korelasi antara sub variabel dengan faktor, yaitu kepada korelasi yang besar. Dengan demikian maka faktor dan anggotanya adalah:

1. Faktor 1 (pengetahuan produk keuangan dan investasi) terdapat tiga sub variabel sebagai anggotanya yaitu knowledge of financial products, ownership of investment products, dan experience of investing products.

2. Faktor 2 (menabung) terdapat dua sub variabel sebagai anggotanya yaitu saving behavior dan saving rate.

3. Faktor 3 (pengetahuan keuangan) terdapat satu sub variabel sebagai anggotanya yaitu financial literacy.

\section{Pembahasan}

Berdasarkan tabel 1 diatas diketahui bahwa nilai $\mathrm{r}$ korelasi antara variabel conceivable use of financial technology dan variabel sosiodemografi sebesar 0,129 dengan nilai sig < 0,05, artinya kedua variabel memiliki korelasi yang positif dengan tingkat hubungan termasuk dalam kategori sangat lemah. Hal ini berarti berarti H1 
diterima karena terdapat hubungan antara conceivable use of financial technology dengan sosiodemografi. Nilai $r$ korelasi antara variabel conceivable use of financial technology dan variabel penilaian diri sebesar -0,053 dengan nilai sig $>0,05$, artinya kedua variabel memiliki korelasi yang negatif dengan tingkat hubungan termasuk dalam kategori sangat lemah. Hal ini berarti $\mathrm{H} 2$ diterima karena terdapat hubungan antara variabel conceivable use of financial technology dan variabel penilaian diri. Nilai $r$ korelasi antara variabel conceivable use of financial technology dan variabel karakteristik finansial sebesar 0,143 dengan nilai sig $<0,05$, artinya kedua variabel memiliki korelasi yang positif dengan tingkat hubungan termasuk dalam kategori sangat lemah. Hal ini berarti $\mathrm{H} 3$ diterima karena terdapat hubungan antara variabel conceivable use of financial technology dan variabel karakteristik finansial.

\section{KESIMPULAN DAN SARAN \\ Kesimpulan}

Berdasarkan dengan analisis yang telah dilakukan, peneliti dapat mengambil beberapa kesimpulan yaitu :

1. Terdapat hubungan yang sangat lemah antara conceivable use of financial technology dengan sosiodemografi.

2. Terdapat hubungan yang sangat lemah antara conceivable use of financial technology dengan penilaian diri.

3. Terdapat hubungan yang sangat lemah antara conceivable use of financial technology dengan karakteristik finansial.

4. Terdapat dua sub variabel baru yang merupakan faktor utama dalam variabel sosiodemografi yaitu, faktor latar belakang belakang rumah tangga (faktor 1) yang beranggotakan marital status, employment, houshold net income, number of children, dan home ownership dan faktor latar belakang pendidikan dan kesehatan (faktor 2) yang beranggotakan highest level of education dan health yang merupakan faktor penting sosiodemografi masyarakat usia produktif Kota Bandung dalam conceivable use of financial technology. Terdapat tiga sub variabel baru yang merupakan faktor utama dalam variabel penilaian diri yaitu, faktor kesabaran dan kepercayaan (faktor 1) yang beranggotakan trust general, trust advisor, dan patience, faktor keputusan pembelian (faktor 2) yang beranggotakan price, transparency, dan finance knowledge, serta faktor risiko (faktor 3) yang beranggotakan risk dan risk tolerance yang merupakan faktor penting penilaian diri masyarakat usia produktif Kota Bandung dalam conceivable use of financial technology. Terdapat tiga sub variabel baru yang merupakan faktor utama dalam variabel karakteristik finansial yaitu, faktor pengetahuan produk keuangan dan investasi (faktor 1) yang beranggotakan knowledge of financial products, ownership of investment products, dan experience of investing products, faktor menabung (faktor 2) yang beranggotakan saving behavior dan saving rate, serta faktor pengetahuan keuangan (faktor 3) yang beranggotakan financial literacy yang merupakan faktor penting karakteristik finansial masyarakat usia produktif Kota Bandung dalam conceivable use of financial technology. 


\section{Saran}

Berikut ini adalah saran yang dapat diberikan berdasarkan hasil analisis data dan pembahasan yang telah dilakukan untuk penelitian selanjutnya :

1. Penduduk usia produktif Kota Bandung diharapkan lebih berkembang dalam mengadopsi teknologi pada bagian keuangan, dengan memperjelas sosiodemografi setiap individu dimulai dari latar belakang rumah tangga serta latar belakang kesehatan dan pendidikan setiap individu. Meningkatkan penilaian diri dengan mawas terhadap kesabaran dan kepercayaan, meningkatkan faktor keputusan pembelian, dan meningkatkan tanggapan terhadap risiko, serta meningkatkan karakteristik finansial setiap individu dimulai dengan meningkatkan pengetahuan produk keuangan dan investasi, serta kegiatan menabung setiap individu.

2. Masyarakat usia produktif Kota Bandung berjumlah 28\% dari jumlah seluruh masyarakat. Diharapkan pemerintah dapat lebih mengembangkan masyarakat dengan memberikan seminar ataupun penyuluhan keuangan guna meningkatkan perekonomian khususnya Kota Bandung dan juga diharapkan pemerintah dapat lebih mendorong masyarakat kota Bandung agar dapat mengadopsi teknologi keuangan melalui peran Bank Indonesia dan Otoritas Jasa Keuangan, serta juga industri perbankan dan berbagai perusahan jasa keuangan yang ada di Indonesia.

3. Objek penelitian ini adalah usia produktif (19-34 tahun) berdasarkan data BPS dan data OJK per Agustus 2019. Akan lebih baik jika objek penelitian ini lebih spesifik pada suatu kelompok/golongan penduduk tertentu seperti golongan usia produktif yang sudah bekerja. Penelitian ini juga memiliki keterbatasan yaitu waktu pelaksanaannya cross section sehingga hanya menggambarkan kondisi pada periode tersebut. Pada penelitian selanjutnya dapat mempertimbangkan untuk penelitian secara berkelanjutan (longitudinal).

\section{DAFTAR PUSTAKA}

Aldás-Manzano, J., Lassala-Navarré, C., Ruiz-Mafé, C., \& Sanz-Blas, S. 2009. The role of consumer innovativeness and perceived risk in online banking usage, International Journal of Bank Marketing 27(1), 53-75.

Amin, H. 2009. An analysis of online banking usage intentions: An extension of the Technology Acceptance Model, International Journal of Business and Society 10(1), 27-40.

Bundesbank, Deutsche. 2016. Die Studie zur wirtschaftlichen Lage privater Haushalte $(P H F)$. Frankfurt am Main.

Davis, F. D. 1989. Perceived Usefulness, Perceived Ease of Use, and User Acceptance of Information Technology. MIS Quarterly 13, 319-339.

Drummer, D., Jerenz, A., Siebelt, P., \& Thaten, M. 2016. Fintech: Challenges and Opportunities - How digitization is transforming the financial sector. McKinsey, Dusseldorf.

Featherman, M. S., \& Pavlou, P. A. 2003. Predicting e-services adoption: A perceived risk facets perspective, International Journal of Human-Computer Studies 59(4), 451-474. 
Financial Stability Board (FSB). 2017. Financial stability implications from Fintech. [online]. Tersedia: http://www.fsb.org/2017/06/financial-stability-implicationsfrom-Fintech/.

$\mathrm{Hu}$ et al. 2019. Adoption Intention of Fintech Services for Bank Users: An Empirical Examination with an Extended Technology Acceptance Model. Symmetry, 11(340), 1-16.

Jonker, N. 2019. What drives the adoption of crypto-payments by online retailers?, Electronic Commerce Research and Applications 35, 100848.

Junger, Moritz \& Mietzner, Mark. 2019. Banking Hoes Digital: The Adoption of Fintech services by German households. Finance Research Letter.

Karaseva, I. 2015. Financial Management. Moscow: Omega-L.

Khominich et al. 2016. Financial Management as a System of Relations of the Enterprise for Highly Efficient Management of its Finances. International Journal of Economics and Financial Issues, 6(S8), 96-101.

Kramer, M. M. 2016. Financial literacy, confidence and financial advice seeking. Journal of Economic Behavior and Organization, 131, 198-217.

Lisovskaya, I. 2006. Fundamentals of Financial Management. Moscow.

Maier, E. 2016. Supply and demand on crowdlending platforms: Connecting small and medium-sized enterprise borrowers and consumer investors, Journal of Retailing and Consumer Services 33, 143-153.

Mallat, N., Rossi, M., Tuunainen, V. K., \& Öörni, A. 2009. The impact of use context on mobile services acceptance: The case of mobile ticketing, Information \& Management 46, 190-195.

Mangin, J.-P. Lévy, Bourgault, N., Calvo-Porral, C., Mesly, O., Telahigue, I., \& Trudel, M. 2014. The Moderating Role of Risk, Security and Trust Applied to the TAM Model in The Offer of Banking Financial Services in Canada, Journal of Internet Banking and Commerce 19(2), 2-21.

Manrai, L. A., \& Manrai, A. K. 2007. A field study of customers' switching behavior for bank services, Journal of Retailing and Consumer Services 14(3), 208-215.

OECD, 2011. Measuring Financial Literacy: Questionnaire and Guidance Notes for Conducting an Internationally Comparable Survey of Financial Literacy, Paris.

OJK, 2019. Perkembangan Fintech Lending Periode Agustus 2019, Indonesia.

Rai, I.A.A. \& Purnawati, N.K., 2017. E-Jurnal Manajemen Unud. Faktor - Faktor yang Mempengaruhi Kredit Pada Bank Umum Swasta Nasional (BUSN) Devisa, 6(11), 5941-5969.

Rasyid, Abdul. 2019. Sekilas Perkembangan Fintech di Indonesia. [online]. Tersedia: https://business-law.binus.ac.id/2019/03/19/sekilas-perkembangan-Fintech-diindonesia/ [19 Oktober 2019]

Rubrik Finansialku. 2019. Mengenal Istilah Fintech. [online]. Tersedia: https://www.finansialku.com/kelebihan-dan-kelemahan-Fintech/ $[19$ Oktober 2019]

Setyowati, Desy. 2019. Tren Dunia: Bank Adopsi Teknologi atau Kolaborasi dengan Fintech. [online]. Tersedia: https://katadata.co.id/berita/2018/10/11/tren-duniabank-adopsi-teknologi-atau-kolaborasi-dengan-Fintech [19 Oktober 2019] 
Skan, J., Dickerson, J., \& Gagliardi, L. 2016. Fintech and the devolving landscape: landing points for the industry. Retrieved from London. Teis.

Smith, A. A., Synowka, D. P. \& Smith, A. 2014. E-commerce quality and adoptive elements of e-ticketing for entertainment and sporting events, International Journal of Business Information Systems 15(4), 450- 487.

Wang, Y.-S., Wang, Y.-M., Lin, H.-H., \& Tang, T.-I. 2003. Determinants of user acceptance of Internet banking: An empirical study, International Journal of Service Industry Management 14(5), 501-519.

$\mathrm{Wu}$, J.-H. \& Wang, S.-C. 2005. What drives mobile commerce? An empirical evaluation of the revised technology acceptance model, Information \& Management 42, 719-729. 